\title{
Plant growth-promoting rhizobacteria enhance the growth and Cd uptake of Sedum plumbizincicola in a Cd-contaminated soil
}

\author{
Wuxing Liu • Qingling Wang • Beibei Wang • Jinyu Hou • \\ Yongming Luo $\cdot$ Caixian Tang $\cdot$ Ashley E. Franks
}

Received: 15 October 2014 / Accepted: 13 January 2015 / Published online: 28 January 2015

(C) Springer-Verlag Berlin Heidelberg 2015

\begin{abstract}
Purpose This study aimed to isolate plant growth-promoting rhizobacteria (PGPR) that exhibit heavy metal resistance to examine their influence on $\mathrm{Cd}$ uptake and soil microbial community structure during phytoremediation.

Materials and methods Heavy metal-tolerant PGPR were isolated from the roots of possible hyperaccumulators using plates with 1-aminocyclopropane-1-carboxylate (ACC) as sole nitrogen source. Minimal inhibitory concentrations (MICs) of each isolate were determined by the plate dilution method. The impacts of isolated PGPR on the growth and Cd accumulation of Sedium plumbizincicola were conducted in a pot experiment. In addition, the effect of PGPR inoculation on the microbial community during phytoextraction by S. plumbizincicola was studied by 454 pyrosequencing. Results and discussion A total of nine Cd-resistant strains were isolated from the roots of $\mathrm{Cd}$ accumulators, and their
\end{abstract}

\footnotetext{
Responsible editor: Jizheng He

W. Liu $(\bowtie) \cdot$ Q. Wang $\cdot$ B. Wang $\cdot$ J. Hou $\cdot$ Y. Luo

Key Laboratory of Soil Environment and Pollution Remediation, Institute of Soil Science, Chinese Academy of Sciences,

Nanjing 210008, China

e-mail: liuwuxin@issas.ac.cn

B. Wang $\cdot$ J. Hou

University of Chinese Academy of Sciences, Beijing 100049, China

Y. Luo

Institute of Coastal Zone Research, Chinese Academy of Sciences,

Yantai 264003, China

C. Tang

Centre for AgriBioscience, La Trobe University, Melbourne

Campus, Bundoora, Victoria 3086, Australia

A. E. Franks

Department of Microbiology, La Trobe University, Melbourne

Campus, Bundoora, Victoria 3086, Australia
}

plant growth-promoting activities were characterized. Isolates were able to produce indole-3-acetic acid (IAA) (28-133 $\left.\mathrm{mg} \mathrm{L}^{-1}\right)$ and solubilize phosphate (65$148 \mathrm{mg} \mathrm{L}^{-1}$ ). In a pot experiment, the inoculation of isolates NSX2 and LCR1 significantly enhanced the growth of and uptake of $\mathrm{Cd}$ by the $\mathrm{Cd}$ hyperaccumulator S. plumbizincicola. 454 pyrosequencing revealed that the inoculation of the PGPR lead to a decrease in microbial community diversity in the rhizopshere during phytoextraction. Specifically, indigenous heavy metal-tolerant PGPR such as Actinospica, Bradyrhizobium, Rhizobium, Mesorhizobium, and Mycobacterium were selectively enriched in the treatments in which PGPR were added. It is suggested that a unique constitution of microbial communities in inoculated treatments plays a key role in enhancing $\mathrm{Cd}$ phytoremediation.

Conclusion Inoculation of strains Rhodococcus erythropolis NSX2 and Cedecea davisae LCR1 could promote $S$. plumbizincicola growth and enhance the remediation efficiency. The introduced PGPR could also affect the indigenous microbial community structure and the diversity in $\mathrm{Cd}$ contaminated soil during phytoremediation.

Keywords Cdcontamination $\cdot$ Hyperaccumulator $\cdot$ Microbial community $\cdot$ PGPR $\cdot$ Phytoextraction $\cdot$ Sedum

\section{Introduction}

Heavy metal contamination of soil and water poses a serious threat to both ecosystems and human health worldwide. Among heavy metals, cadmium $(\mathrm{Cd})$ is considered as one of the most toxic contaminants in soils due to its high mobility and low permissible exposure limit (Sheng et al. 2008). Conventional remediation methods for metal remediation such as soil washing, stabilization, acid leaching, ion 
exchange, or electrochemical processes are costly, inefficient, and often have a negative impact on soil biological system (Lasat 2002; Wu et al. 2012). Over the past two decades, phytoremediation has been used as a cost-effective and environmentally friendly method for the remediation of slightly or moderately contaminated soils (Wuana and Okieimen 2011). The success of phytoremediation depends on the potential of the plants to produce high biomass yield while withstanding the metal stress (Rajkumar et al. 2012). However, many heavy metal-accumulating species used in phytoremediation are limited by slow growth and small biomass yields which restricts large-scale remediation. To date, more than 400 species of metal hyperaccumulator plants have been extensively studied for metal phytoextraction (Boularbah et al. 2006). Sedum plumbizincicola has been confirmed as a hyperaccumulator plant because of its remarkable capacity to withstand the metal stress in polluted soils and cadmium (Cd) and extract zinc ( $\mathrm{Zn}$ ) from polluted soils in south and east China (Wu et al. 2008).

Apart from heavy metal toxicity, plant growth may be limited in contaminated soils due to environmental stresses including drought, salinity, and nutrient deficiency. Overcoming such environmental stresses and the promotion of plant growth is essential for the optimum performance of phytoremediation. Plant growth-promoting rhizobacteria (PGPR) are a group of beneficial rhizosphere bacteria which can enhance the tolerance of plants against toxicity and promote plant growth through the production of plant growthpromoting (PGP) factors such as siderophores, indole-3acetic acid (IAA), and 1-aminocyclopropane-1-carboxylate (ACC) deaminase (Glick et al. 2007). Therefore, the application of PGPR is a promising approach to improving the growth of heavy metal hyperaccumulators and the efficiency of phytoremediation.

Several studies have demonstrated that the inoculation of PGPR can improve the growth and heavy metal uptake of hyperaccumulators (Guo and Chi 2014). The survival of introduced PGPR and subsequent changes to the rhizopshereassociated microbial community structure during phytoremediation of heavy metal-contaminated soils are considered to be key factors for successful phytoremediation (Jeong et al. 2013; Piromyou et al. 2011). Recently, molecular biology techniques (e.g., T-RFLP and PCR-denaturing gradient gel electrophoresis (DGGE)) have been applied to investigate the interactions between the heavy metal-resistant PGPR and the plant in heavy metal-contaminated soils (Chen et al. 2013). However, these techniques do not provide high-resolution taxonomic information and focus on the most abundant members of the microbial population. Without highresolution taxonomic insight, important small-scale community components may be missed. Recent advances in sequencing technology, such as pyrosequencing, and its application in evaluating bacterial diversity allows greater levels of in-depth analysis of the microbial community that overcomes some of these problems. However, the response of a rhizosphereassociated microbial community of a heavy metal hyperaccumulator to an introduced PGPR during phytoremediation of heavy metals, to our knowledge, has not been investigated using the pyrosequencing method.

The objectives of the present study were to (1) isolate heavy metal-tolerant PGPR which can utilize ACC as sole nitrogen source; (2) evaluate PGP traits of the isolated strains; (3) evaluate the impacts of isolated PGPR on the growth and $\mathrm{Cd}$ accumulation of $S$. plumbizincicola, a $\mathrm{Cd}$ hyperaccumulator in a pot experiment; and (4) compare the microbial community structure in soil with and without inoculation of PGPR during Cd phytoextraction.

\section{Materials and methods}

\subsection{Isolation of Cd-tolerant PGPR}

Fresh root samples $(1 \mathrm{~g})$ were taken from Sedum arboretum, Sedum X Graptosedum, Crassula multicava, and Carpobrotus rossii that had been grown for 120 days in $20 \mathrm{mg} \mathrm{kg}^{-1} \mathrm{Cd}$ contaminated soils in a glasshouse. These plants are Australian native plant species which had greater shoot biomass production, and $C$. rossii can hyperaccumulate $\mathrm{Cd}$ (Zhang et al. 2014). Roots were washed in sterile water before homogenization in $1 \mathrm{~mL}$ of sterile water using sterile mortar and pestle. Serial dilutions of this suspension were prepared $\left(10^{-1}-10^{-3}\right)$, and $100 \mu \mathrm{L}$ spread plated onto the SMN medium agar (Belimov et al. 2005) supplemented with $20 \mathrm{mg} \mathrm{L}^{-1}$ of $\mathrm{CdCl}_{2}$. The SMN medium $\mathrm{pH}$ was adjusted to 7.0 before autoclaving and ACC $\left(0.5 \mathrm{~g} \mathrm{~L}^{-1}\right)$ was added as the sole nitrogen source after autoclaving. After incubation for 7 days at $30{ }^{\circ} \mathrm{C}$, individual colonies of distinct morphology were isolated through streak plating on the LB medium (Bertani 1954) supplemented with $20 \mathrm{mg} \mathrm{L}^{-1}$ of $\mathrm{CdCl}_{2}$.

\subsection{Heavy metal resistance of isolates}

Minimal inhibitory concentrations (MICs) for each isolate were determined by the plate dilution method as adopted by Malik and Jaiswal (2000). Isolates, capable of utilizing ACC as sole nitrogen source, were grown in sucrose-minimal salt low-phosphate (SLP) medium (Jiang et al. 2008) comprising $\left(\mathrm{g} \mathrm{L}^{-1}\right.$ ) the following: sucrose 10; $\left(\mathrm{NH}_{4}\right)_{2} \mathrm{SO}_{4} 1 ; \mathrm{K}_{2} \mathrm{HPO}_{4}, 0.5$; $\mathrm{MgSO}_{4}, 0.5 ; \mathrm{NaCl}, 0.1$; yeast extract, $0.5 ; \mathrm{pH} 7.2$, supplemented with the metal cations: $\mathrm{Cd}^{2+}\left(\mathrm{CdCl}_{2}\right) ; \mathrm{Cu}^{2+}\left(\mathrm{CuCl}_{2}\right)$; and $\mathrm{Zn}^{2+}\left(\mathrm{ZnCl}_{2}\right)$ at a range of concentrations $(0-$ $1000 \mathrm{mg} \mathrm{kg}^{-1}$ ) when required. Stock solutions of the metal salts were prepared in double deionized water and sterilized by $0.22 \mu \mathrm{m}$ filter. The SLP agar plates without metals were used as controls. All experiments were conducted in triplicate. Cultures were incubated at $28^{\circ} \mathrm{C}$ for 7 days. 


\subsection{Identification of isolated PGPR}

The 16S ribosomal RNA (rRNA) gene was extracted and amplified by PCR as described by Lee et al. (2010) and sequenced at Majorbio Bio-pharm Technology Co., Ltd (Shanghai, China). The obtained sequences were compared to the 16S rDNA nucleotide sequences in the GenBank database by BLASTN. Multiple sequence alignment was done using CLUSTAL X software (Thompson et al. 1997).

\subsection{IAA and phosphate solubilization assay}

Quantitative estimation of IAA was conducted according to Salkowski colorimetric assay (Glickmann and Dessaux 1995). The ability to produce IAA of the strains with and without Ltryptophan was studied for the reason that L-tryptophan is generally considered as an IAA precursor (Mohite 2013). The bacterial isolates were screened for phosphate solubilization ability using Pikovskaya (PVK) broth (Nautiyal 1999) with $5 \mathrm{~g} \mathrm{~L}^{-1} \mathrm{Ca}_{3}\left(\mathrm{PO}_{4}\right)_{2}$ as the only P source. The solubilized phosphate in the culture was quantified by the ammonium molybdate spectrophotometric method as described by Payne (1994).

\subsection{Soil and S. plumbizincicola propagation}

Soil was collected from the top $0-20 \mathrm{~cm}$ of soil from Xiangtan city, Hunan province, China ( $\left.27^{\circ} 44^{\prime} 10^{\prime \prime} \mathrm{N}, 112^{\circ} 56^{\prime} 23^{\prime \prime} \mathrm{E}\right)$. The soil was air-dried and passed through a $2-\mathrm{mm}$ sieve and had soil pH (1:2.5 soil/water) 4.70, organic matter $32.1 \mathrm{~g} \mathrm{~kg}^{-1}$, total $\mathrm{N} 1.75 \mathrm{~g} \mathrm{~kg}^{-1}$, total $\mathrm{K} 9.15 \mathrm{~g} \mathrm{~kg}^{-1}$, total $\mathrm{P} 0.37 \mathrm{~g} \mathrm{~kg}^{-1}$, available $\mathrm{N} 106 \mathrm{mg} \mathrm{kg}^{-1}$, available $\mathrm{P} 19.2 \mathrm{mg} \mathrm{kg}^{-1}$, available $\mathrm{K} 57 \mathrm{mg} \mathrm{kg}^{-1}$, total $\mathrm{Cd} 0.53 \mathrm{mg} \mathrm{kg}^{-1}$, and total $\mathrm{Zn}$ $132 \mathrm{mg} \mathrm{kg}^{-1}$, determined using the routine methods ( $\mathrm{Lu}$ 1999). Stem cuttings of $10 \mathrm{~cm}$ in height of S. plumbizincicola were prepared from middle section of vigorous shoots of 1-year-old plants grown in non-contaminated soil.

\subsection{Pot experiment}

To evaluate the effect of the isolated PGPR on the growth and Cd phytoremediation potential of $S$. plumbizincicola, a pot experiment was conducted in growth chambers and consisted of 10 treatments (nine isolated PGPR inoculated treatments and an uninoculated control) in four replicates. Individual pots were planted with five cuttings of S. plumbizincicola in $1.5 \mathrm{~kg}$ air-dry soil supplemented with $\left(\mathrm{NH}_{4}\right)_{2} \mathrm{SO}_{4}, \mathrm{~K}_{2} \mathrm{HPO}_{4}$, and $\mathrm{KCl}$ giving final rates $\left(\mathrm{mg} \mathrm{kg}^{-1}\right)$ of $\mathrm{N} 250, \mathrm{P} 100$, and $\mathrm{K} \mathrm{150}$. The soil water content was adjusted to $20 \%(w / w)$ during the experiment.

For the PGPR-inoculated treatments, the strains were pelleted by centrifugation at $9000 \mathrm{rpm}$ for $15 \mathrm{~min}$ at $4{ }^{\circ} \mathrm{C}$ from cultures at the exponential growth phase in the LB medium. Cell pellet was washed with sterile distilled water, and an inoculum was prepared by re-suspending pelleted cells in sterile distilled water to obtain a density of $10^{9}$ colony-forming units (cfus) $\mathrm{mL}^{-1}$. Bacterial suspensions $\left(15 \mathrm{~mL}\right.$ pot $\left.^{-1}\right)$ were mixed with the soil before planting. Plants were grown for 3 months in a glasshouse.

At harvest, the plants were cut at the soil surface and washed with deionized water. Soil from each pot was sampled and stored at $-4{ }^{\circ} \mathrm{C}$. The fresh and dry weights of the shoot were then measured. Dry plant samples $(\sim 0.5 \mathrm{~g})$ were digested using a mixture of $6 \mathrm{~mL} \mathrm{HNO}_{3}$ and $4 \mathrm{~mL} \mathrm{HClO}_{4}$, and concentrations of $\mathrm{Cd}$ was determined using AAS (Varian SpectrAA 220 FS). A certified reference material (GBW07603, provided by the Institute of Geophysical and Geochemical Exploration, Langfang, Hebei Province, China) was used for quality control (Wu et al. 2012).

\subsection{Soil DNA extraction and PCR amplification}

Soil DNA was extracted using a soil DNA kit (Fast DNA SPIN for soils, MP Biomedicals, Solon, $\mathrm{OH}$ ) and checked the DNA on agarose gels (Moreira 1998). The primer pair 515f and 907r (515 F 5'-GTGCCAGCMGCCGCGG-3', 907R 5'-CCGTCAATTCMTTTRAGTTT-3') were utilized to amplify a 392 base pair fragment of the 16S rRNA gene for 454 pyrosequencing (Xu et al. 2013). Sequencing was conducted by Majorbio Bio-pharm Technology Co., Ltd (Shanghai, China).

\subsection{Pyrosequencing data processing}

The 16S rRNA gene sequence data were analyzed by the pyrosequencing pipeline tools available from the Ribosomal Database Project (RDP) and MOTHUR version 1.24.1 (Schloss et al. 2011). Counts of the number of the sequences of each cluster within each sample were converted to frequencies by dividing the number of counts of each cluster by total number of sequences generated within each sample. The $16 \mathrm{~S}$ rRNA sequences were first trimmed, and then, sequences with $<200$ bases were removed from the data sets with MOTHUR. Sequences from each data set, ranging from 6381 to 10,865 individual sequences, were submitted to the RDP aligner tool for species identification. Further processing and operational taxonomic unit (OTU)-based analyses were then carried out using the MOTHUR v.1.24.1 suite of algorithms for sequence processing and diversity analysis, including commands for identifying, unique sequences, filtering, sequence alignment, generating distance matrices, clustering of sequences into OTUs with a confidence threshold of $80 \%$. The resulting clusters were assessed at $97 \%$ similarity to provide the data needed for diversity analysis. Several indices (OTUs, Chao, 
and Ace) for sample size of 6000 sequence were calculated using the MOTHUR program at the cutoff of $97 \%$.

\subsection{Statistical analysis}

Statistical analysis was conducted with SPSS 19.0 software. Duncan's multiple range tests were used to compare the means of treatments; variability in the data was expressed as the standard errors. All analyses were performed at the $p<0.05$ level.

\section{Results}

\subsection{Isolation and identification of Cd-tolerant PGPR}

Nine Cd-tolerant isolates which could use ACC as the sole nitrogen source were obtained from the root of healthy plants grown in a Cd-contaminated soil. The nine strains showed a range of tolerance to the heavy metals $\mathrm{Cd}, \mathrm{Zn}$, and $\mathrm{Cu}$. MICs varied from 0 to $1000 \mathrm{mg} \mathrm{L}^{-1}$ on plate assays against $\mathrm{Cd}, \mathrm{Cu}$, and $\mathrm{Zn}$, respectively (Table 1). Among the nine strains, CCM2 exhibited the highest broad range tolerance to heavy metals with growth observed on plates containing $1000 \mathrm{mg} \mathrm{Zn} \mathrm{L}^{-1}$, $200 \mathrm{mg} \mathrm{Cd} \mathrm{L}^{-1}$ and $150 \mathrm{mg} \mathrm{Cu} \mathrm{L}^{-1}$. 16S rRNA gene sequence of isolates NSX1 (from $S$. X Graptosedum), NCR3 (from C. rossii), and LCR9 (from $C$. rossii) showed the highest homology to Entobacter ludwigii, NSX2 (from S. X Graptosedum) and CCM2 (from C. multicava) to Rhodococcus erythropolis, NSE2 ( $S$. arboretum) to Enterobacter cancerogenus, NCR1 and LCR 1 (from C. rossii) to Cedecea davisae, and NCR4 (from C. rossii) to Arthrobacter sp. (Table 1).

Table 1 Host plant and taxa of bacterial isolates and their minimum inhibitory concentrations (MIC) of heavy metals

\begin{tabular}{|c|c|c|c|c|c|}
\hline \multirow[t]{2}{*}{ Isolate } & \multirow[t]{2}{*}{$\begin{array}{l}\text { Host plant of } \\
\text { origin }\end{array}$} & \multirow[t]{2}{*}{ Taxa } & \multicolumn{3}{|c|}{$\begin{array}{l}\text { MIC of heavy } \\
\text { metals }\left(\mathrm{mg} \mathrm{L}^{-1}\right)\end{array}$} \\
\hline & & & $\mathrm{Cd}$ & $\mathrm{Cu}$ & $\mathrm{Zn}$ \\
\hline NSX1 & S. X Graptosedum & Enterobacter ludwigii & 50 & 0 & 200 \\
\hline NSX2 & S. X Graptosedum & $\begin{array}{l}\text { Rhodococcus } \\
\text { erythropolis }\end{array}$ & 20 & 100 & 600 \\
\hline NSE2 & S. arboretum & $\begin{array}{l}\text { Enterobacter } \\
\quad \text { cancerogenus }\end{array}$ & 150 & 0 & 200 \\
\hline NCR1 & C. rossii & Cedecea davisae & 100 & 200 & 800 \\
\hline NCR3 & C. rossii & Enterobacter ludwigii & 50 & 150 & 800 \\
\hline NCR4 & C. rossii & Arthrobacter sp. & 50 & 50 & 800 \\
\hline CCM2 & C. multicava & $\begin{array}{l}\text { Rhodococcus } \\
\text { erythropolis }\end{array}$ & 200 & 150 & 1000 \\
\hline LCR1 & C. rossii & Cedecea davisae & 50 & 200 & 200 \\
\hline LCR9 & C. rossii & Enterobacter ludwigii & 20 & 100 & 150 \\
\hline
\end{tabular}

\subsection{IAA production and phosphate solubilization}

All nine isolates were able to produce IAA in the absence of L-tryptophan (Fig. 1). Production of IAA varied from $28 \mathrm{mg} \mathrm{L}^{-1}$ (NSE2) to $144 \mathrm{mg} \mathrm{L}^{-1}$ (NCR3). All nine isolated strains displayed the potential for phosphate solubilization (Fig. 2). The maximum phosphate solubilization was achieved at $148 \mathrm{mg} \mathrm{L}^{-1}$ by strain NSE2. All the strains were shown to decrease the medium $\mathrm{pH}$ ranging from 4.93 to 6.10 , compared to the uninoculated control $(\mathrm{pH}$ 7.6). The maximum $\mathrm{pH}$ decrease was also achieved by isolate NSE2.

3.3 Influence of bacterial inoculation on plant growth and cadmium uptake

The effects of isolated PGPR on the growth and Cd uptake of S. plumbizincicola are summarized in Table 2. Compared to the control, the inoculation of NSX2 and LCR1 significantly increased the dry weight of plant shoots (by 22.0 and $26.9 \%$, respectively). However, $\mathrm{Cd}$ concentrations in shoots of all inoculated treatments were not significantly different from that of the control. The total amount of $\mathrm{Cd}$ phytoextracted $\left(\mathrm{mg} \mathrm{pot}^{-1}\right.$ ) was calculated by multiplying the shoot dry weight by shoot $\mathrm{Cd}$ concentration. The inoculation of NSX2 and LCR1 significantly increased total $\mathrm{Cd}$ in the shoot (by 14 and $18 \%$, respectively), compared with the control. These two soil samples and control were selected for further 454 pyrosequencing to determine their microorganism communities.

3.4 Evolution of microbial community structure and diversity by inoculations

The 16S rRNA gene survey for genetic diversity produced a total of 26,667 sequence reads. The control, LCR1, and NSX2 treatments individually produced 10,909, 7427 and 8331 sequence reads, respectively. At a $97 \%$ similarity cutoff, the

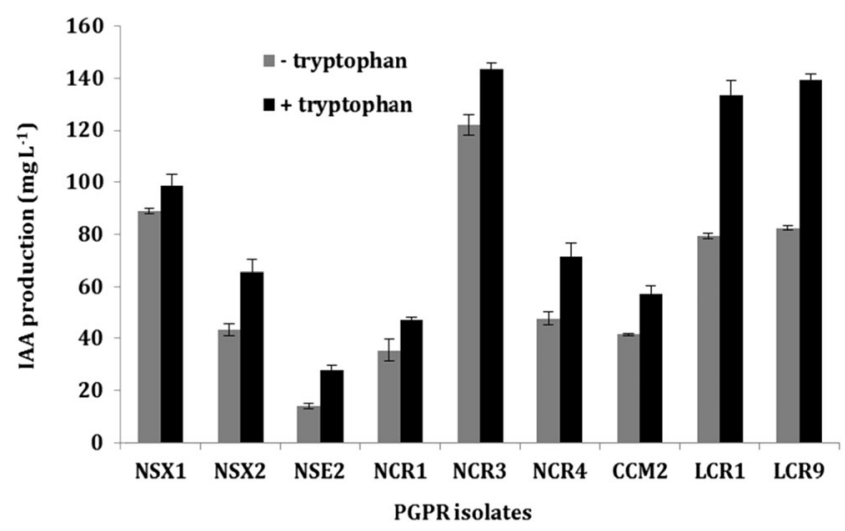

Fig. 1 Quantitative estimation of IAA production by isolates of plant growth-promoting rhizobacteria (PGPR) in the LB medium. Values are means $\pm \operatorname{SD}(n=3)$ 
Fig. 2 Quantitative estimation of phosphate solubilization of selected isolates of plant growthpromoting rhizobacteria (PGPR) in liquid Pikovskaya's medium after 5 days of incubation. Values are means $\pm \mathrm{SD}(n=3)$

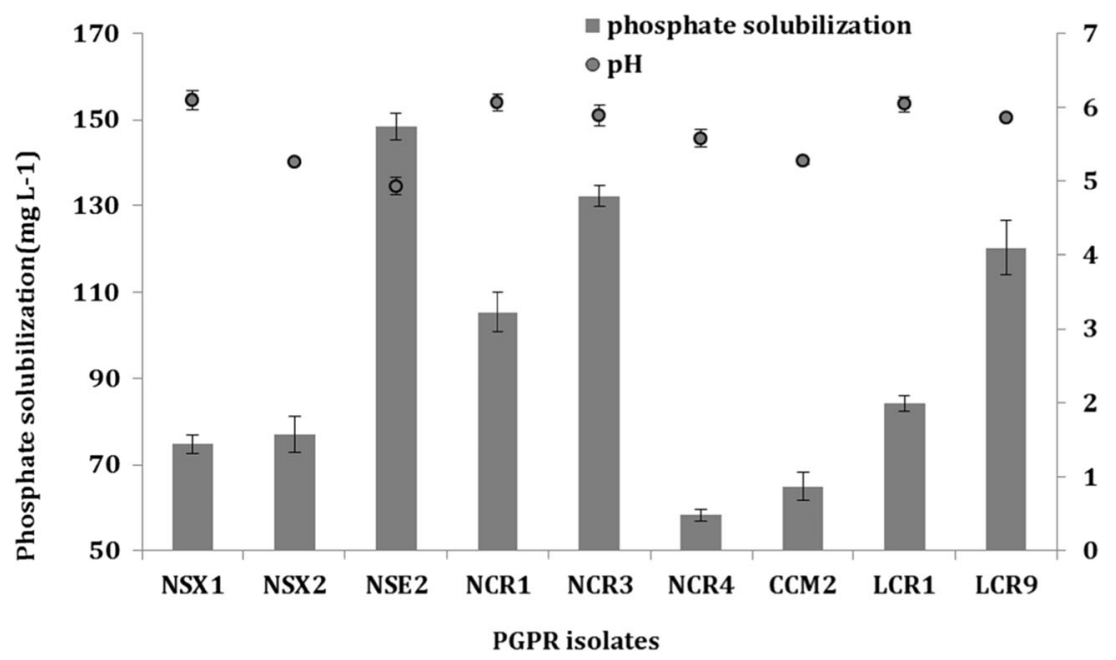

reads from the control, LCR1, and NSX2 treatments were binned into 2197, 1521, and 1845 operational taxonomic units respectively. Within rarefaction curves, the distance value of 0.03 (97\% similarity) was used as the point at which differentiation occurs at the specie level (Bowman et al. 2012). Rarefraction curves (figure not shown) indicate that the analysis of species richness was an accurate representation of bacterial diversity due to the samples trending toward a plateau at a 0.03 cutoff at 6000 reads. The inoculation of the PGPR decreased the richness of microbial community after 3 months. The Ace and Chao index showed a clear drop compared to the control treatment (Table 3).

The phylogenetic spectrum classification of sequences from the soil samples at the phylum level accounted for $78.2,82.9$, and $82.8 \%$ in the control, LCR1, and NSX2 treatments, respectively. Proteobacteria, Actinobacteria, and Firmicutes were comprised the top three phyla groups, which

Table 2 Influence of selected isolates on the plant growth and the uptake (mg) of Cd by S. plumbizincicola grown for 3 months

\begin{tabular}{llll}
\hline Treatments & $\begin{array}{l}\text { Shoot dry weight } \\
\left(\text { g plant }^{-1}\right)\end{array}$ & $\begin{array}{l}\text { Shoot Cd } \\
\text { concentration } \\
\left(\mathrm{mg} \mathrm{kg}^{-1}\right)\end{array}$ & $\begin{array}{l}\text { Shoot Cd } \\
\text { accumulation }_{\left(\mathrm{mg} \mathrm{pot}^{-1}\right)}\end{array}$ \\
\hline Control & $11.7 \pm 1.3 \mathrm{ab}$ & $42.7 \pm 0.7 \mathrm{abc}$ & $0.50 \pm 0.02 \mathrm{a}$ \\
NSX1 & $11.6 \pm 0.5 \mathrm{a}$ & $45.8 \pm 0.9 \mathrm{c}$ & $0.53 \pm 0.02 \mathrm{ab}$ \\
$\mathrm{NSX} 2$ & $14.3 \pm 1.3 \mathrm{c}$ & $41.3 \pm 0.9 \mathrm{ab}$ & $0.59 \pm 0.02 \mathrm{~cd}$ \\
NSE2 & $12.7 \pm 2.6 \mathrm{abc}$ & $43.4 \pm 1.2 \mathrm{bc}$ & $0.55 \pm 0.03 \mathrm{abcd}$ \\
NCR1 & $13.3 \pm 1.3 \mathrm{abc}$ & $42.1 \pm 1.2 \mathrm{ab}$ & $0.56 \pm 0.02 \mathrm{abcd}$ \\
NCR3 & $12.9 \pm 2.1 \mathrm{bc}$ & $41.7 \pm 0.8 \mathrm{ab}$ & $0.54 \pm 0.01 \mathrm{abc}$ \\
NCR4 & $11.6 \pm 0.8 \mathrm{a}$ & $43.3 \pm 0.3 \mathrm{bc}$ & $0.50 \pm 0.01 \mathrm{a}$ \\
$\mathrm{CCM} 2$ & $11.6 \pm 0.6 \mathrm{a}$ & $43.1 \pm 0.9 \mathrm{abc}$ & $0.50 \pm 0.01 \mathrm{a}$ \\
LCR1 & $14.9 \pm 1.3 \mathrm{c}$ & $41.5 \pm 0.8 \mathrm{ab}$ & $0.57 \pm 0.02 \mathrm{bcd}$ \\
LCR9 & $12.9 \pm 1.0 \mathrm{bc}$ & $42.7 \pm 1.4 \mathrm{abc}$ & $0.55 \pm 0.03 \mathrm{abcd}$
\end{tabular}

Values are means \pm standard errors $(n=4)$. Means sharing the same letter do not differ significantly from each other at $p<0.05$ on average comprised $26.2,15.8$, and $10.9 \%$ in the uninoculated soil population, respectively. The remaining phylotypes were associated with Acidobacteria $(9.0 \%)$, Chloroflexi (6.8\%), Planctomycetes (3.7\%), Bacteroidetes (3.6\%), Gemmatimonadetes $(0.57 \%)$, Verrucomicrobia $(0.51 \%)$, Armatimonadetes $(0.39 \%)$, Crenarchaeota $(0.29 \%)$, Euryarchaeota $(0.20 \%)$, TM7 (0.14\%), Nitrospirae $(0.10 \%)$, and BCR1 $(0.05 \%)$. The dominant phylum, Proteobacteria, decreased to 23.6 and $24.8 \%$ in the LCR 1 and NSX2 treatments, respectively. The next two dominant phyla Actinobacteria and Firmicutes increased to 20.1 and $16.9 \%$, and 11.6 and $12.2 \%$ in the LCR 1 , and NSX2 treatments, respectively. Planctomycetes increased to 6.0 and $5.2 \%$ in the LCR1 and NSX2 treatments, respectively, almost doubled the control. The reads for the phylum Acidobacteria and Euryarchaeota also increased to 9.84 and $10.72 \%$, and 0.46 and $0.30 \%$ in the LCR 1 and NSX2 treatments, separately (Fig. 3a).

Furthermore, genus level analysis was also conducted to examine functional evolution of the community (Jeong et al. 2013). The Gp3 Acidobacteria population was found to increase in the LCR1 and NSX2 treatments (1.57 and $1.84 \%$, respectively) compared to the uninnoculated soil (1.22\%). The inoculation of LCR1 increased Oryzihumus, Mycobacterium, and Actinospica (Actinobacteria) by 31.5, 30.2 , and $227.5 \%$, respectively, while the inoculation of NSX2 increased Burkholderia, Bradyrhizobium, Mesorhizobium, and Rhizobium (Proteobacteria) by 27.2, 28.3, 350.0, and 550.0\%, respectively (Fig. 3b).

Although both of NSX2 and LCR1 were isolated from the roots of plants grown in a soil contaminated with high levels of heavy metals including $\mathrm{Cd}$ and $\mathrm{Zn}$, only inoculated $R$. erythropolis NSX2 $(0.18 \%$, relative to $0.01 \%$ of the control) was found in soil 3 months after initial inoculation while $C$. davisae LCR1 was not detected. 
Table 3 Richness estimators to predict species numbers in soil without (control) or with inoculation of LCR1 and NSX2 ${ }^{\mathrm{a}}$

\begin{tabular}{lcrr}
\hline Samples & OTUs $^{\text {b }}$ & ACE & Chao \\
\hline Control & 2197 & 10,083 & 5744 \\
LCR1 & 1521 & 6224 & 3945 \\
NSX2 & 1845 & 6262 & 3868 \\
\hline
\end{tabular}

${ }^{a}$ The richness estimators and diversity indices were calculated based on equal number of sequences (6000 sequences) which were randomly selected from each sample

${ }^{\mathrm{b}}$ Operational taxonomic units (OTUs) were calculated based on $97 \%$ sequence similarity

\section{Discussion}

Bioremediation strategies using a combination of PGPR and plants have been demonstrated to a cost-effective way for promoting plant growth and protecting plants from heavy metal toxicity (Guo and Chi 2014). The PGPR strains must be tolerant to heavy metals constitutively or adaptively by exclusion, physical sequestration, detoxification, and complexion (Nies 2003). In this study, nine Cd-tolerant PGPRs were isolated from the roots of $\mathrm{Cd}$ accumulator plants (S. arboretum, S. X Graptosedum, C. multicava, and C. rossii) grown on Cdcontaminated soil (Zhang et al. 2014). On the basis of colony morphology and 16S rRNA gene sequence, the nine strains were identified as E. ludwigii (NSX1, NCR3, and LCR9), $R$. erythropolis (NSX2 and CCM2), E. cancerogenus (NSE2), C. davisa (NCR1 and LCR1), and Arthrobacter sp. (NCR4) (Table 1).

In addition to tolerance to heavy metals, these strains showed the PGP properties of ACC deaminase and IAA production as well as phosphate solubilization. The PGPR containing ACC deaminase can hydrolyze ACC, the immediate precursor of ethylene, to a-ketobutyric acid and ammonia, and in this way promote plant growth (Glick et al. 1998). This present study obtained nine strains of rhizobacteria that could utilize ACC as the sole nitrogen source, indicating that these isolates could produce ACC deaminase and utilize ACC as nitrogen source. Bacterial produced IAA has previously been reported to contribute to decreasing metal stress, promoting plant growth, and increasing the total metal uptake (Dell'Amico et al. 2008). Phosphate solubilization is important for improving plant growth in P-deficient soils. All the strains were shown to decrease the medium $\mathrm{pH}$ compared to the uninoculated control ( $\mathrm{pH}$ 7.6), which has previously been linked to solubilization of calcium phosphate. In this present study, all nine isolates had the capacity of producing IAA and solubilizing phosphate (Figs. 1 and 2). In soils inoculated with PGPR, a slightly decrease of soil pH (data not shown) was observed, indicating that the phytoavailable $\mathrm{Cd}$ would increase and thus its uptake by plants. To the best of our knowledge, among these strains, only $R$. erythropolis was reported as a Cd-tolerant species (Becerra-Castro et al. 2012), but this is the first study reporting the potential of $R$. erythropolis to increase plant growth in metal-contaminated soils.

It is noticed that isolate NCR3, which produced the highest IAA, did not significantly increase the growth or $\mathrm{Cd}$ phytoextraction of $S$. plumbizincicola. However, the greatest effect on plant growth and $\mathrm{Cd}$ accumulation was found for the LCR1 and NSX2-inoculated treatments (Table 2). Similarly, Belimov et al. (2001) did not find a correlation between the PGP ability and plant growth. Their experiments showed that the nine tested strains significantly varied in ACC deaminase activity of cell-free extracts while only slight or no effects were observed in quartz sand culture in the absence of $\mathrm{CdCl}_{2}$, and only three strains P. putida Am2, P. putida Bm3,
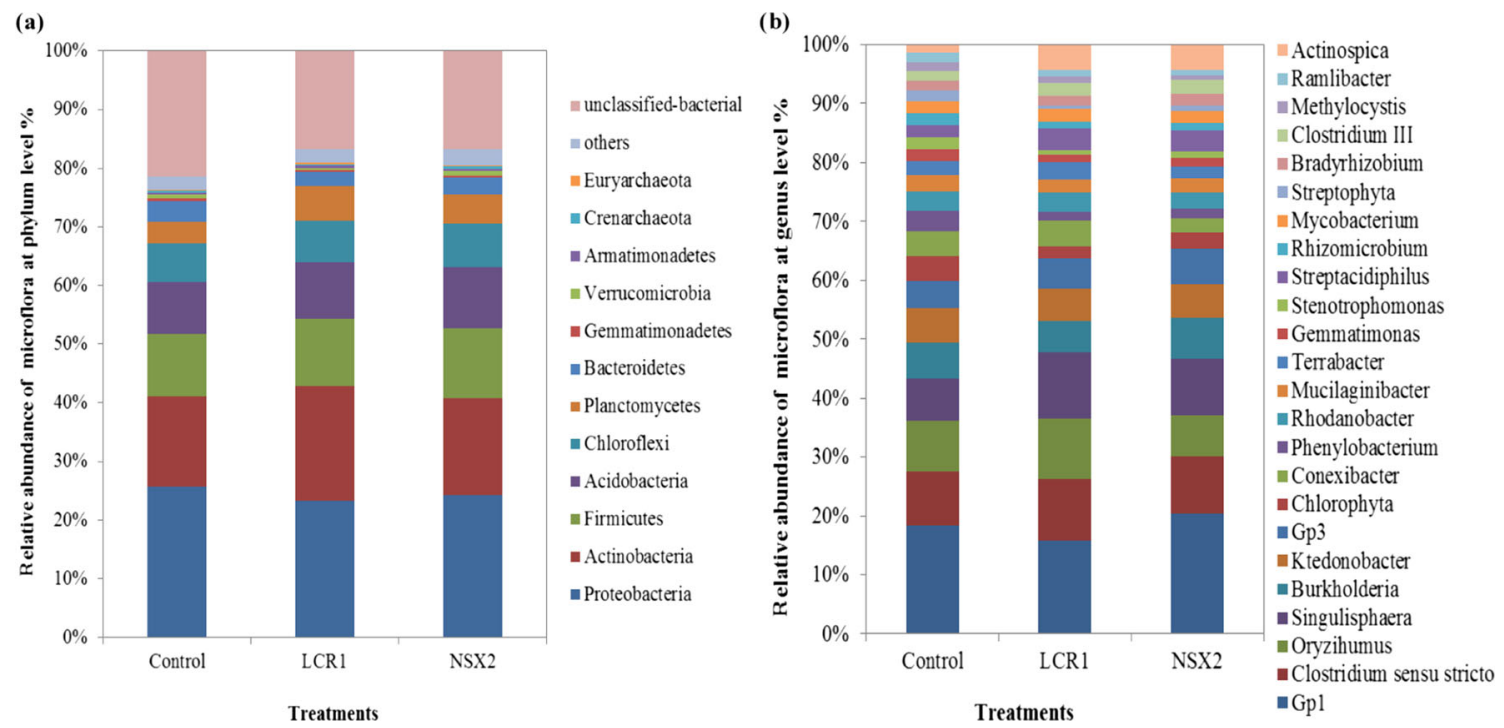

Fig. 3 Relative abundance of microflora at phylum (3a) and genus (3b) levels in soils of different inoculating treatments 
and $P$. brassicacearum Am3 significantly increased root elongation (by 14-20\%) under Cd stress. The explanation for the lack of correlation between the PGP ability and plant growth might be that other bacterial properties associated with their taxonomic position could also affect the interaction of rhizobacteria with plant roots.

Apart from the inoculated PGPR, the microbial population of the soil also plays a significant role in phytoremediation of heavy metals in contaminated soils by affecting heavy metal mobility, bioavailability to the plant, and enhancement of the phytoremediation processes (Jing et al. 2007). Here, we adopted a pyrosequencing approach to elucidate the change of microbial community during phytoremediation in the Cdcontaminated soil, which is more sensitive than the previously reported PCR-DGGE method (Jeong et al. 2013). This study demonstrated that the introduced PGPR had clear impacts on the microbial community structure and diversity (Fig. 3a, b). The richness estimators (OTUs, Ace, and Chao) revealed that the inoculation of PGPR decreased the diversity of microbial community (Table 3). Furthermore, the inoculation of LCR1 and NSX2 markedly enhanced the relative abundance of the phylum Planctomycetes in the Cd-contaminated soil. In a previous study, the richness and diversity of Planctomycetes were shown to be driven by $\mathrm{pH}$ and to have strong spatial and seasonal variations linked to environmental conditions (Pollet et al. 2011). In the present study, the slight decrease of soil $\mathrm{pH}$ (date not shown) might lead to an increase of the relative abundance of Planctomycetes in the inoculated treatments.

The inoculated bacterial $R$. erythropolis NSX2 increased from $0.01 \%$ (control) to $0.18 \%$, which exhibited various PGP features such as ACC deaminase, indole, and siderophore production ability (Trivedi et al. 2007). In addition, diverse symbiotic microorganisms including Bradyrhizobium, Rhizobium, Mesorhizobium are now being used worldwide as bioinoculants to promote plant growth under stresses of various heavy metals (Wani and Khan 2010). These indigenous genera increased inordinately in soil inoculated with NSX2. All of these bacterial groups could not only increase the heavy metal mobilization, and production of IAA, siderophores, $\mathrm{HCN}$, and ammonium, and $\mathrm{P}$ solubilization, but also increase biomass (plant and microorganism), nitrogen content, and accumulation of metals (Wani et al. 2007). Additionally, a few taxa showed a positive response to the soil even when they were present only in relative low abundance. Mycobacterium and Actinospica significantly increased to 0.69 and $1.31 \%$, separately, in soil inoculated with C. davisae LCR1 which were accounted for 0.53 and $0.40 \%$ in the uninoculated soil, both of which were identified as PGPR (Bhattacharyya and Jha 2012; Tsavkelova et al. 2005). That is, the percentage of the species responsible for $\mathrm{Cd}$ phytoavailability becomes more abundant in both of the inoculated soils.
Although both of NSX2 and LCR1 were inoculated to the Cd-contaminated soil, only inoculated $R$. erythropolis NSX2 $(0.18 \%$, relative to $0.01 \%$ of the control) was found in soil 3 months after initial inoculation while $C$. davisae LCR1 was not detected. The reason may be that the strain NSX2 was isolated from S. X Graptosedum (Table 1) which was the same family with $S$. plumbizincicola used in this experiment, but C. davisae LCR1 was separated from C. rossii. Nevertheless, soil microorganisms were only monitored at the end of the remediation which was difficult to reflect the survival dynamics of introduced bacteria in the process of phytoremediation. We suspected that the PGP properties of inoculated PGPR combined with the changes of microorganism community, especially of species responsible for Cd phytoavailability, leading to the better growth of S. plumbizincicola and Cd phytoextraction. The survival dynamics of introduced bacteria in the process of phytoremediation needs further study.

Although above discussion highlights the effectiveness of PGPR in enhancing the growth and $\mathrm{Cd}$ uptake of S. plumbizincicola, PGPR C. davisae LCR1 was not detected in soil 3 months after initial inoculation. This could be attributed to competition for the inoculated PGPR with the indigenous microflora as well as various kinds of environmental stresses (Brockwell et al. 1995). Encapsulation of the bacteria may be an effective alternative to free cell dispersal. It is reported that encapsulating bacteria could survive in soil and be released into soil in a controllable manner, so that long-term effects can be optimized (Wu et al. 2011). Furthermore, the use of multi-strain inoculants could be a good strategy that enables organisms to successfully survive and maintain themselves in communities (Andrews et al. 1991). Each strain in the multi-strain consortium may compete effectively with indigenous population in the rhizosphere and enhance plant growth with its partners. It has been reported that coinoculation of Bradyrhizobium and PGPR microorganisms significantly improved soybean growth and its yield components as compared with the sole application of Bradyrhizobium (Wasule et al. 2007).

\section{Conclusions}

In this study, nine Cd-tolerant PGPR were isolated from the roots of heavy metal accumulators. All isolates had varying levels of IAA production and phosphate solubilization. Among the isolates, NSX2 and LCR1 were found to significantly enhance the Cd uptake of S. plumbizincicola. Based on 16S rRNA gene sequence, NSX2 and LCR1 were identified as $R$. erythropolis and $C$. davisae, respectively. Pyrosequencing analysis of the microbial community after inoculation of test isolates indicates that the PGPR could invoke changes of the microbial community structure and diversity during the experimental period. These findings 
demonstrate that the information on the activity of introduced bacteria in soil and microbial community variation is required for effective bacteria-associated phytoextraction.

Acknowledgments We thank the National High Technology Research and Development Program of China (863 Program) (No. 2012AA06A204), Jiangsu Provincial Natural Science Foundation of China (BK2012891), the International Scientific Collaborative Program of the Ministry of Science and Technology of China (2010DFA92360), and National Natural Science Foundation of China (41001182) for financial support. Tang and Liu were also supported by an Australian Research Council Linkage Project (LP100100800).

\section{References}

Andrews AE, Lawley B, Pittard AJ (1991) Mutational analysis of repression and activation of the tyrP gene in Escherichia coli. J Bacteriol 173:5068-5078

Becerra-Castro C, Monterroso C, Prieto-Fernández A, Rodríguez-Lamas L, Loureiro-Viñas M, Acea MJ, Kidd PS (2012) Pseudometallophytes colonising $\mathrm{Pb} / \mathrm{Zn}$ mine tailings: a description of the plant-microorganism-rhizosphere soil system and isolation of metal-tolerant bacteria. J Hazard Mater 217-218:350-359

Belimov AA, Safronova VI, Sergeyeva TA, Egorova TN, Matveyeva VA, Tsyganov VE, Borisov AY, Tikhonovich LA, Kluge C, Preisfeld A, Dietz KJ, Stepanok VV (2001) Characterization of plant growth promoting rhizobacteria isolated from polluted soils and containing 1-aminocyclopropane-1-carboxylate deaminase. Can J Microbiol 47:642-652

Belimov AA, Hontzeas N, Safronova VI, Demchinskaya SV, Piluzza G, Bullitta S, Glick BR (2005) Cadmium-tolerant plant growthpromoting bacteria associated with the roots of Indian mustard (Brassica juncea L. Czern.). Soil Biol Biochem 37:241-250

Bertani G (1954) Studies on lysogenesis III. Superinfection of lysogenic Shigella dysenteriae with temperate mutants of the carried phage. J Bacteriol 67:696-707

Bhattacharyya PN, Jha DK (2012) Plant growth-promoting rhizobacteria (PGPR): emergence in agriculture. World J Microb Biot 28:13271350

Boularbah A, Schwartz C, Bitton G, Aboudrar W, Ouhammou A, Morel JL (2006) Heavy metal contamination from mining sites in South Morocco: 2. Assessment of metal accumulation and toxicity in plants. Chemosphere 63:811-817

Bowman JS, Rasmussen S, Blom N, Deming JW, Rysgaard S, SicheritzPonten T (2012) Microbial community structure of Arctic multiyear sea ice and surface seawater by 454 sequencing of the 16S RNA gene. ISME J 6:11-20

Brockwell J, Bottomley PJ, Thies JE (1995) Manipulation of rhizobia microflora for improving legume productivity and soil fertility: a critical assessment. Plant Soil 174:143-180

Chen ZJ, Sheng XF, He LY, Huang Z, Zhang WH (2013) Effects of root inoculation with bacteria on the growth, $\mathrm{Cd}$ uptake and bacterial communities associated with rape grown in Cd-contaminated soil. J Hazard Mater 244:709-717

Dell'Amico E, Cavalca L, Andreoni V (2008) Improvement of Brassica napus growth under cadmium stress by cadmium-resistant rhizobacteria. Soil Biol Biochem 40:74-84

Glick BR, Penrose DM, Li JP (1998) A model for the lowering of plant ethylene concentrations by plant growth-promoting bacteria. J Theor Biol 190:63-68
Glick BR, Cheng ZY, Czarny J, Duan J (2007) Promotion of plant growth by ACC deaminase-producing soil bacteria. Eur J Plant Pathol 119: 329-339

Glickmann E, Dessaux Y (1995) A critical examination of the specificity of the salkowski reagent for indolic compounds produced by phytopathogenic bacteria. Appl Environ Microbiol 61:793-796

Guo J, Chi J (2014) Effect of Cd-tolerant plant growth-promoting rhizobium on plant growth and Cd uptake by Lolium multiflorum Lam. and Glycine max (L.) Merr. in Cd-contaminated soil. Plant Soil 375: 205-214

Jeong S, Moon HS, Shin D, Nam K (2013) Survival of introduced phosphate-solubilizing bacteria (PSB) and their impact on microbial community structure during the phytoextraction of Cd-contaminated soil. J Hazard Mater 263:441-449

Jiang CY, Sheng XF, Qian M, Wang QY (2008) Isolation and characterization of a heavy metal-resistant Burkholderia $s p$. from heavy metal-contaminated paddy field soil and its potential in promoting plant growth and heavy metal accumulation in metal-polluted soil. Chemosphere 72:157-164

Jing YD, He ZL, Yang XE (2007) Role of soil rhizobacteria in phytoremediation of heavy metal contaminated soils. J Zhejiang Univ Sci B 8:192-207

Lasat MM (2002) Phytoextraction of toxic metals. J Environ Qual 31: 109-120

Lee SC, Kim SH, Park IH, Chung SY, Chandra MS, Yong LC (2010) Isolation, purification, and characterization of novel fengycin $\mathrm{S}$ from Bacillus amyloliquefaciens LSC04 degrading-crude oil. Biotechnol Bioprocess Eng 15:246-253

Lu RK (1999) Analytical methods of soil agricultural chemistry. China Agriculture Science Technology Press, Beijing

Malik A, Jaiswal R (2000) Metal resistance in Pseudomonas strains isolated from soil treated with industrial wastewater. World J Microb Biot 16:177-182

Moreira D (1998) Efficient removal of PCR inhibitors using agaroseembedded DNA preparations. Nucleic Acids Res 26:3309-3310

Mohite B (2013) Isolation and characterization of indole acetic acid (IAA) producing bacteria from rhizospheric soil and its effect on plant growth. J Soil Sci Plant Nut 13:638-649

Nautiyal CS (1999) An efficient microbiological growth medium for screening phosphate solubilizing microorganisms. FEMS Microbiol Lett 170:265-270

Nies DH (2003) Efflux-mediated heavy metal resistance in prokaryotes. FEMS Microbiol Rev 27:313-339

Payne SM (1994) Detection, isolation, and characterization of siderophores. Bacterial pathogenesis, Part A: Identification and regulation of virulence factors. Methods Enzymol 235:329-344

Piromyou P, Buranabanyat B, Tantasawat P, Tittabutr P, Boonkerd N, Teaumroong N (2011) Effect of plant growth promoting rhizobacteria (PGPR) inoculation on microbial community structure in rhizosphere of forage corn cultivated in Thailand. Eur J Soil Biol 47:44-54

Pollet T, Tadonléké RD, Humbert JF (2011) Spatiotemporal changes in the structure and composition of a less-abundant bacterial phylum (Planctomycetes) in two perialpine lakes. Appl Environ Microbiol 77:4811-4821

Rajkumar M, Sandhya S, Prasad MNV, Freitas H (2012) Perspectives of plant-associated microbes in heavy metal phytoremediation. Biotechnol Adv 30:1562-1574

Schloss PD, Gevers D, Westcott SL (2011) Reducing the effects of PCR amplification and sequencing artifacts on 16S rRNA-based studies. PLoS One 6:e27310

Sheng XF, He LY, Wang QY, Ye HS, Jiang CY (2008) Effects of inoculation of biosurfactant-producing Bacillus sp. J119 on plant growth and cadmium uptake in a cadmium-amended soil. J Hazard Mater $155: 17-22$ 
Thompson JD, Gibson TJ, Plewniak F, Jeamougin F, Higgins DG (1997) The Clustal_X windows interface: flexible strategies for multiple sequence alignment aided by quality analysis tools. Nucleic Acids Res 25:4876-4882

Trivedi P, Pandey A, Sa T (2007) Chromate reducing and plant growth promoting activies of psychrotrophic Rhodococcus erythropolis MtCC 7905. J Basic Microb 47:513-517

Tsavkelova EA, Cherdyntseva TA, Netrusov AI (2005) Auxin production by bacteria associated with orchid roots. Microbiology 74:46-53

Wani PA, Khan MS (2010) Bacillus species enhance growth parameters of chickpea (Cicer arietinum L.) in cromium stressed soils. Food Chem Toxicol 48:3262-3267

Wani PA, Khan MS, Zaidi A (2007) Effect of metal tolerant plant growth promoting Bradyrhizobium sp. (vigna) on growth, symbiosis, seed yield and metal uptake by greengram plants. Chemosphere 70:36-45

Wasule D, Wadyalkar S, Buldeo A (2007) Effect of phosphate solubilizing bacteria on role of Rhizobium on nodulation by soybean. In: Velazquez E, Rodriguez-Barrueco C, editors. First International Meeting on Microbial Phosphate Solubilization. pp 139-42

Wu LH, Li N, Luo YM (2008) Phytoextraction of heavy metal contaminated soil by Sedum plumbizincicola under different agronomic strategies. Proceedings of the 5th International Phytotechnology Conference, pp 49-50

Wu ZS, Zhao YF, Kaleem I, Li C (2011) Preparation of calcium-alginate microcapsuled microbial fertilizer coating Klebsiella oxytoca Rs-5 and its performance under salinity stress. Eur J Soil Biol 47:152-159

Wu LH, Li Z, Akahane I, Liu L, Han CL, Makino T, Luo YM, Christie P (2012) Effects of organic amendments on $\mathrm{Cd}, \mathrm{Zn}$ and $\mathrm{Cu}$ bioavailability in soil with repeated phytoremediation by Sedum plumbizincicola. Int J Phytorem 14:1024-1038

Wuana RA, Okieimen FE (2011) Heavy metals in contaminated soils: a review of sources, chemistry, risks and best available strategies for remediation. ISRN Ecol. doi:10.5402/2011/402647

$\mathrm{Xu} \mathrm{K}$, Tang Y, Ren C, Zhao K, Sun Y (2013) Diversity and abundance of $n$-alkane-degrading bacteria in the near-surface soils of a Chinese onshore oil and gas field. Biogeosciences 10:2041-2048

Zhang CJ, Sale PWG, Doronila AI, Clark GJ, Livesay C, Tang C (2014) Australian native plant species Carpobrotus rossii (Haw.) Schwantes shows the potential of cadmium phytoremediation. Environ Sci Pollut Res. doi:10.1007/ s11356-014-2919-3 